\title{
VESTÍGIOS PÓS-DRAMÁTICOS NO TRABALHO “DESVIO" DO ERRO GRUPO DE FLORIANÓPOLIS: ENTRELAÇAMENTOS CÊNICOS ENTRE ESPAÇO FICCIONAL E ESPAÇO SOCIAL
}

\author{
Elisa Schmidt; Elisza Peressoni Ribeiro (Iniciação Científica) \\ Heloisa Marina da Silva (Iniciação Científica) \\ Stephan Arnulf Baumgärtel (Orientador)
}

\begin{abstract}
RESUMO: Partindo da concepção do drama como proposta por Peter Szondi, este artigo levanta características da concepção do teatro e da dramaturgia pós-dramáticas. O foco principal está na relação híbrida que essa estética propõe ao transformar espaços sociais em espaços cênicos, ficcionais, baseando sua produção na situação teatral, ou seja, na relação que o espetáculo constrói com o público. Queremos mostrar que as concepções de dramaturgia, de ação cênica e de atuação dramática são historicamente específicas.
\end{abstract}

PALAVRAS-CHAVES: Teatro Pós-Dramático; Dramaturgia Pós-Dramática; Espaços Cênicos

Partindo da concepção do drama como proposta por Peter Szondi, este artigo levanta características da concepção do teatro e da dramaturgia pós-dramáticas. O foco principal está na relação híbrida que essa estética propõe ao transformar espaços sociais em espaços cênicos, ficcionais, baseando sua produção na situação teatral, ou seja, na relação que o espetáculo constrói com o público. Queremos mostrar que as concepções de dramaturgia, de ação cênica e de atuação dramática são historicamente específicas. Reconhecer este fato ajuda a entender uma boa parte da produção teatral contemporânea, como por exemplo o trabalho Desvio do Erro Grupo ${ }^{1}$ de Florianópolis, o qual nos propomos a fazer uma breve análise fundamentada a partir da estética do teatro pós-dramático.

O conceito de drama sofreu diversas modificações desde sua origem grega até a contemporaneidade, passando pelo drama burguês. Para Szondi, o drama moderno apresenta como característica da ação dramática a

\footnotetext{
1 O Erro Grupo foi criado em março de 2001, em Florianópolis, e atualmente é composto por 5 integrantes sendo que, dentre eles, alguns foram alunos da UDESC. O espetáculo Desvio, assistido em 21 de março de 2007 ocorreu no centro de Florianópolis, e foi apresentado também em outras cidades brasileiras. Mais informações sobre o grupo podem ser encontradas no site www.errogrupo.com.br.
}

DAPesquisa, Florianópolis, v.3 n.5, p.926-937, 2008. 
personalidade individual do ser humano como centro e força actancial da ação, expressa essencialmente através dos diálogos. Em relação ao teatro dramático, Pavis (2003, p. 242) afirma que "a mimese é a imitação de uma coisa e a observação da lógica narrativa”. Neste sentido, mimesis dramática implica num estilo de atuação essencialmente naturalista. Desta forma, o drama burguês se apóia na criação de caracteres ficcionais sendo que o conflito está na ação entre indivíduos autônomos numa história representada com início, meio e fim, cujo tempo configurado ao espectador é o tempo presente. A cena ocorre em palco italiano, com o intuito de criar uma atmosfera ilusória aos espectadores, exigindo destes uma atenção passiva e contemplativa em relação ao espetáculo, sem estimular, portanto, um pensamento crítico por parte do público. Enquanto gênero teatral, o drama tornou-se hegemônico a partir do século XVIII.

Seguindo a análise de Szondi, Lehmann afirma que: "o drama está intrinsecamente relacionado com a noção de dialética, dialética no sentido de um conflito que tem uma progressão e que vai caminhar depois, mais à frente, para uma síntese. Não há como dissociar o conceito do drama dessa dialética".(2005, p.10). Esta concepção da ação dialética faz com que a ação cênica se concentre na construção da ficção e na comunicação verídica entre os personagens. Portanto, a atuação focaliza o universo dramático e representacional, ou seja, podemos concluir que tanto do ponto de vista estético quanto da atuação, a criação naturalista de um universo ficcional sobrepõe-se à criação de uma relação comunicativa entre palco e platéia.

A partir da virada do século XIX para o século XX essa estrutura dramática passa a entrar em crise, exemplo disso são as propostas cênicas que surgem do teatro grotesco de Meyerhold, passando pelas peças didáticas de Brecht, até as propostas elaboradas pelo Living Theatre. Dentro de todas essas propostas cênicas de vanguarda do século XX, a estética do happening é a que mais rompe com as estruturas do drama. Seu surgimento serviu para quebrar o gesso da arte dramática que petrificava as manifestações artísticas banalizadas pelo mercantilismo. No capítulo sobre o happening do seu livro EI nuevo teatro, De Marinis (1987, p. 63-87) estabelece cinco características para sua estética: $\mathrm{O}$ happening abandona por completo a estrutura dramática 
tradicional que é fundamentalmente narrativa, seu roteiro se baseia em ações a serem executadas, sem no entanto, estabelecer uma ordem para elas, fazendo assim que no caráter verbal prevaleça os valores fonéticos sobre os semânticos. O tempo e o lugar de representação não são definidos como no drama. A atuação é performática, onde as ações são compostas ao improviso. Os elementos cênicos ganham valor, dando aos objetos uma importância maior ou igual a do ator. A quarta parede do teatro italiano é inexistente, fazendo com que os intérpretes tenham maior contato com o público, trazendo para a encenação características híbridas no intuito de misturar ficção com a realidade.

Partindo dessas características a representação performática enfatiza a efemeridade e o caráter de processo da obra artística. Não se trata de uma ação mimética no sentido aristotélico, mas do próprio ator como veículo da informação. Em suma, ela desloca o eixo da apresentação do sistema comunicacional interno (entre os personagens fictícios) para o sistema comunicacional externo (entre os personagens/atores e os espectadores).

Neste sentido, a mudança da relação entre o trabalho cênico e o espectador, de uma estética exclusivamente representacional para uma estética em grande parte performática, é fundamental para delimitarmos conceitos válidos ao termo teatro pós-dramático. Os elementos traçados por Szondi para o teatro dramático não são anulados por completo, contudo as idéias de conflito e de caráter da personagem são articulados de forma diferente da forma do drama. Incorporando reflexões do happening, o caráter da atuação pós-dramática passa a fazer uso de características performáticas e testa as relações entre ficção e vida pragmática. O tempo configurado ao espectador não é mais o presente da ficção, mas o presente da recepção, ele se torna então consciente do seu próprio olhar. Nas palavras de Patrick Primavesi:

Deve-se compreender o conceito "teatro pós-dramático", segundo o estudo fundamental de Hans-Thies Lehmann, não de uma forma dogmática, como se fosse uma renúncia final do texto dramático. Antes, serve como uma ferramenta de trabalho para descrever várias formas novas de fazer teatro, com certa proximidade à performance, que seguem outros princípios do que aqueles das encenações tradicionais de uma 
obra dramática. Não se trata simplesmente de um estilo único, mas de um processo transformador mais longo, que conseguia liberar os parâmetros elementares do teatro (espaço, luz, corpo, movimento, gesto, voz, etc.) da sua submissão à obra dramática. Se as formas teatrais pós-dramáticas criam espaços experimentais para percepções não-habituais, o fazem, sobretudo, porque possibilitam uma nova consciência da situação que o teatro significava, desde sempre, enquanto prática cultural: o acontecimento de um encontro entre pessoas que apresentam algo e pessoas que assistem a apresentação. (PRIMAVESI, 2004, p. 09, Trad. Stephan Baumgärtel)

A questão que se coloca dentro dessa perspectiva teatral é: porque se tornou tão interessante atualmente trabalhar simultaneamente dentro de ambas as lógicas mencionadas? Até que ponto a relação entre essas duas estéticas fala a respeito da sociedade contemporânea?

Podemos, para responder a tais questionamentos, identificar reflexões de Guy Debord sobre a nossa sociedade contemporânea enquanto 'sociedade de espetáculo'. O que Debord propõe é que a sociedade atual vive num mundo onde as fronteiras entre real e espetacular, entre fato e ficção, não são mais passíveis de serem delimitadas, "[...] a realidade vivida é materialmente invadida pela contemplação do espetáculo e retoma em si a ordem espetacular à qual adere de forma positiva. [...] a realidade surge no espetáculo, e o espetáculo é real". (Debord, 1997, p. 15).

O teatro contemporâneo parece querer indagar toda essa qualidade espetacular que está inserida no próprio cotidiano, ou seja, evidenciar o espetáculo público do qual fazemos parte sem nem se quer nos darmos conta.

O teatro pós-dramático pode, portanto, ser melhor compreendido a partir desse conceito de Debord. Logo, podemos dizer que a situação teatral, o encontro entre intérpretes e público, representa o seu elemento mais interessante e nevrálgico pois permite evidenciar e problematizar a relação entre arte e vida, e discutir as possibilidades que o teatro têm de relacionar o seu público de forma crítica com a sociedade contemporânea. Para atingir tal finalidade algumas dessas manifestações realizam suas apresentações em espaços não convencionais, outras trabalham com pessoas que nunca atuaram 
nem imaginaram um dia exercer a função de ator ${ }^{2}$, ou ainda, relativizam a relação temporal (podemos tomar como exemplo algumas performances que chegam a durar dias, cabendo ao espectador escolher o tempo que ele participará do espetáculo). Essas características, amplamente exploradas nas montagens contemporâneas, conferem à situação teatral um certo pragmatismo, aproximando-as mais do real, do cotidiano, sem deixar de insistir na própria qualidade ficcional. O desafio é estabelecer uma tensão produtiva entre a encenação enquanto encontro social e apresentação espetacular.

Percebemos, a partir dessa tendência de confrontar a lógica dos elementos teatrais, que especialmente o papel do público é questionado; ele passa a ser um integrante ativo do espetáculo, e é justamente esse questionamento que faz surgir a interrogação referente aos limites entre arte e vida. Através da problematização desse argumento pretende-se também atingir reflexões referentes ao papel do espectador na sociedade em si. Oscar Cornago (2007, p. 27) afirma que

A primeira personagem de uma obra é o próprio espectador; e fazer o público tornar-se consciente disso é uma conquista de um teatro que tem preferido tirá-lo de sua condição de consumidor passivo ao qual a sociedade do espetáculo o reduziu. [...] A obra triunfa na medida em que consegue criar um sentimento de coletividade, fazendo com que o público esqueça sua condição de comprador e consumidor de espetáculos, para fazê-lo sentir-se parte desse algo; o efeito cotidiano de assistir a uma obra teatral é transformado na ação central desse espetáculo.

Para colocar o espectador no centro da situação teatral, mistura-se uma técnica que podemos chamar de hiper-realista com técnicas metateatrais. 0 meta-teatro inserido num contexto cotidiano e pragmático, como o da vida urbana "[...] torna-se uma forma de antiteatro onde a fronteira entre a obra e a vida se esfumaça”. (PAVIS, 2003, p.240) A encenação se torna, nesse caso, uma atividade auto-reflexiva, criando uma metáfora da vida como teatro,

\footnotetext{
2 Um exemplo dessa escolha é o trabalho Chácara Paraíso (www.chacaraparaiso.org) da diretora argentina Lola Arias e do diretor alemão Stefan Kaegi. Trabalho esse concebido na forma de instalação e que apresenta como proposta a diluição de aspectos documentais e ficcionais. Essa mistura é atingida uma vez que o projeto conta com a participação de pessoas que não são atores (selecionados através de anúncios em jornais, todas ligadas ao universo policial brasileiro),e que remontam cenas de "sua própria bibliografia", no espetáculo.
} 
metáfora essa que passa a ser o seu tema principal, e, através dessa proposta, o jogo cênico passa a problematizar a relação da ficção com a sociedade contemporânea. (Idem)

Temos por outro lado a técnica hiper-realista que se configura no sentido de tornar obscuro os elementos ficcionais frente aos da vida pragmática, ou seja, o espaço ficcional se dilui na vida pragmática. Tal técnica é usada quando, por exemplo, um personagem ficcional se confunde com os espectadores, ou quando localidades reais (ruas, rios, etc.) se tornam espaços cênicos.

Dessa maneira os espetáculos pós-dramáticos acabam se efetuando dentro da lógica hiper-realista da própria "sociedade do espetáculo", porém a compreensão a cerca desse fenômeno teatral específico distingue-se do que Debord chamou de espetáculo. A diferença está no fato de que o intuito dos teatros criados dentro da lógica representacional pós-dramática é justamente fazer do público um público consciente das lógicas espetaculares existentes no teatro e na vida, e neste sentido, co-responsável pela apresentação desses espetáculos, enquanto que o espetáculo da vida diária, sugerido por Debord, opera justamente no sentido contrário, o de alienação e de entorpecimento perceptual. Isso ocorre porque, segundo Helga Finter (2007, p. 18), o espetáculo presente na vida cotidiana pretende ser real, natural, ao passo que uma encenação pós-dramática sempre volta a frisar a sua teatralidade; ainda que seu material de representação e suas tensões surjam da própria situação teatral, onde o encontro entre realidade pragmática e ficcional é interrogado. Nas palavras de Finter (Idem) "[...] a teatralidade do campo estético se distingue da do cotidiano em vários pontos: [...] ela permite a este [0 espectador] uma crítica da sociedade do espetáculo, já que o espectador pode fazer nela a experiência do seu desejo de olhar".

O processo passa a ser então o principal enfoque nas montagens contemporâneas, às vezes sobressaindo-se em relação a qualidade artística do trabalho. Quando falamos em processo, estamos querendo destacar também, e principalmente, o encontro que se dá entre o espectador e o espetáculo. 0 grande trunfo deste teatro contemporâneo está na qualidade da relação social que se estabelece entre os participantes no momento da reapresentação, pois acredita-se que é precisamente esse momento de encontro/troca que surtirá no 
espectador o pensamento crítico. O intuito no entanto não é modificar a realidade concretamente, mas sim fazer refletir a partir da provocação onde 0 espectador se torna parte da obra. Inverte-se portanto o papel atribuído ao espectador da Sociedade do Espetáculo de Debord. A relação com 0 espectador, seu papel e função dentro da obra teatral, bem com a pretendida diluição da fronteira entre arte e vida é, nesse sentido, o cerne da discussão no que diz respeito à situação teatral do teatro pós-dramático, e é também com esses aspectos e não mais com a matriz dramática que o Erro Grupo de Florianópolis trabalha.

Este grupo caracteriza-se por trabalhar com a união de linguagens artísticas, mesclando a arte com o cotidiano e fazendo lugares públicos tornarem-se espaço de criação e ação estética, em espetáculos tais como "Adelaide Fontana" (2000), "Carga Viva" (2002) e seu mais novo trabalho "Enfim um líder" (2008). Suas propostas tornam a separação entre realidade e ficção frágil. Em seu espetáculo "Desvio", que é encenado por ruas da cidade, há um enfoque na situação teatral que mistura elementos dramáticos e representacionais com elementos hiper-realistas e meta-teatrais

O enredo consiste na representação de um assassinato, uma morte anunciada que está prestes a ocorrer, porém que não ocorre durante o caminho percorrido pela apresentação. O centro ideológico encontra-se no modo da apresentação e nas várias situações teatrais que este constrói. "Desvio" é um trabalho que fala através da forma, e não da fábula e por isso são tão importantes os encontros entre atores e espectadores.

Durante o percurso, o público é conduzido por uma narradora que porta um microfone e uma caixa de som, e assim narra não somente os acontecimentos imediatos, mas também aqueles que estão por vir, já dando os primeiros indícios de que a fábula tem menor importância. Sua irmã é aquela que a ajuda e também que toma conta da vítima, exercendo a função de um técnico de palco. O personagem que representa a vítima sente-se maravilhado com a cidade, como se a visse pela primeira vez, estimulando que, também aqueles que vivem ali percebam as construções e os lugares com mais detalhe. O assassino chama a atenção, pois, se por um lado parece um personagem real, típico das ruas centrais das grandes cidades brasileiras, por outro parece muito fazer parte do espetáculo. A dúvida sobre a qualidade 
ficcional dessa personagem permanece até o final do espetáculo. De forma semelhante, outro personagem surge trazendo consigo dúvidas sobre sua origem real ou pragmática. Trata-se de um homem jovem, de terno, que é escolhido pela narradora para puxar por algum tempo a caixa de som. Ele aceita sua tarefa, porém não sem espanto, e só é possível identificar que faz parte do elenco quando começa a distribuir "programas" do espetáculo. O último personagem também com aspectos hiper-realistas é um violonista sentado na rua, tocando e cantando, como se por coincidência o espetáculo passasse por este transeunte. Ao final, no entanto, ele aparece outra vez tocando e cantando, e assim continua mesmo após a instrução da narradora, que pede ao público que circule.

O espaço cênico entre realidade e ficção: A cidade, desta forma, torna-se palco e lugar da representação do assassinato. Suas ruas servem de cenografia, assim como seus prédios, lojas e suas paredes, nas quais cartazes são colados com frases que serão ditas pelos atores. O espetáculo então interage com os elementos urbanos que se transformam em adereços. Para o público aparece a questão de como separar o local cotidiano do local ficcional, uma vez que eles se fundem. Não existe, apesar dos elementos hiper-realistas já citados, a intenção de que a representação se passe por uma ação pragmática, não há a intenção deste ilusionismo, pelo contrário, a narradora constantemente lembra que o que está se passando é uma representação, enfatizando o caráter meta-teatral do espetáculo. A análise de alguns destes elementos ajuda a entender melhor a criação de signos híbridos.

Os personagens entre realidade e ficção: $O$ assassino escora-se nas pessoas, apoiando-se e dormindo sobre elas e sobre postes e paredes da cidade, carregando um travesseiro de fronha branca. Um momento importante é aquele em que, após uma pausa proposta pela narradora para que se pense na situação, ela convida aqueles que quiserem continuar a lhe seguirem, e avisa para lembrarem depois que tiveram opção, deixando claro que o que ocorre é uma encenação. Neste instante sua irmã dirige-se à vítima que se encontra atrás da narradora. De costas esta narra todos os movimentos dos outros dois, uma cena de violência, como se já fosse previsto o que acontece, como se aquilo fosse uma repetição do sempre. Ela utiliza uma voz sem emoção, midiática, neutra, que só fala o que está programado. O fim do 
espetáculo é inusitado, a narradora agradece ao público, porém não pede aplausos, pede que as pessoas "circulem" indicando que a representação acabou, mas a cidade ainda existe e é a mesma, independente do que acaba de se passar. O cenário da peça, que é o espaço urbano, a cidade, é um elemento intensificador e colabora para que todos os outros elementos construam signos híbridos. A vítima, quando se maravilha com a cidade também a reclama enquanto cenário, ao mesmo tempo que alerta o público sobre o espaço social. Jogando com a técnica hiper-realista os personagens reproduzem a representação de um assassinato e ao mesmo tempo estão presentes enquanto indivíduos que transitam, criando uma relação com a platéia que é tanto de ignorância quanto de cumplicidade.

A política teatral enquanto política de percepção: As funções e objetivos destes signos criados pelos elementos descritos acima confluem para a discussão do cotidiano e para o questionamento social. $O$ espetáculo colabora para a discussão política através da relação emocional das pessoas com seu ambiente, trazendo a tona características propostas por Debord a respeito da sociedade do espetáculo. A discussão política foge da sua forma mais comum de ocorrência no teatro, a forma direta, as vezes até panfletária, ocorrendo agora na relação de percepção do público a respeito do que é "social". Assim o espetáculo fala através de sua forma sobre a situação social. $O$ assassino que parece bêbado se mistura às pessoas que assistem e muitas vezes até as incomoda quando se escora nelas, causando um desconforto que prepondera até que elas descobrem que ele faz parte do espetáculo e talvez, por isso, não seja mais tão incômodo ter que escorá-lo, e sim engraçado ou vergonhoso. Sendo assim, este personagem abre caminho para que o público pense que qualquer um possa ser um ator, e aqueles que assistem já não podem mais ter certeza de quem é personagem fictício ou quem é apenas um transeunte. $O$ personagem violinista também colabora para causar esta confusão no público. A cena de violência é claramente um momento que remete à narração dos telejornais atuais que são estruturados dramaturgicamente como um melodrama, no qual as partes tristes preponderam, porém o final é sempre composto de uma boa notícia, o desenlace é sempre emocional. Através da mídia as pessoas mantém sua posição de voyeurista, evitando a consciência de que eles compõem o cenário 
social. O espetáculo, ao reproduzir ao vivo momentos que são assistidos no sofá e, por isso, ironicamente parecem mais ficcionais do que a encenação feita pelos atores naquele momento, faz com que as pessoas assistam aquilo que vêem como algo distante, aproximando a realidade imaginada a partir dos telejornais da realidade presenciada. Ou seja, o espetáculo problematiza as relações midiáticas, que na verdade se tornam não-relações, pois as informações midiáticas são representações, e não chegam a ser experiências vividas, "em todos os tipos possíveis de instrumentos, indicadores e telas, o que se vê são os signos mais ou menos abstratos; aspectos essenciais da realidade escapam dos sentidos corporais" (LEHMANN, 2007, p. 366). O espaço urbano, por sua vez, é configurado enquanto cenário ficcional e ambiente de encontros sociais, a esquina pela qual alguém passa todos os dias, e que nunca é percebida, vira palco de um acontecimento que mistura o pragmático e o midiático de forma meta-teatral. Desta forma, ao mesmo tempo que ocorre a encenação acontece também a vida social e ambas se contaminam. Através da encenação o espaço urbano retoma sua qualidade de espaço de encontro e deixa de ser lugar de trânsito. A fala final da narradora: "circulem", evitando os aplausos, trata da relação palco-público, desconstruindo a divisão tradicional e transformando separação em entrelaçamento. Este pedido indica que a representação não acabou, que ela continua, sempre, recomeça e vive com a cidade, é uma representação de milhares de atores. Desta forma a encenação realiza um dos objetivos principais do teatro pósdramático de fazer o público se perceber enquanto ser atuante. Esta fala final permite que os signos híbridos criados durante toda a peça não se percam e contribui para que se dilua completamente os limites entre ação ficcional e prática social.

Podemos agora esclarecer a relação do espetáculo "Desvio" acerca da nossa pergunta inicial sobre os motivos e possibilidades de usar esta estética híbrida no contexto da sociedade contemporânea. Neste espetáculo o público é questionado objetivamente sobre a realidade e seus acontecimentos. A criação de signos híbridos traz dúvidas e incertezas frente ao que é, porém poderia não ser ficção, uma vez que esta ficção está tão mesclada à visão cotidiana que se confunde ao que parecia, a priori, ser a realidade "real" e incontestável. Os signos híbridos permitem a reflexão crítica e são constantemente explorados 
no espetáculo justamente com essa função: problematizar o que parece comum, questionar o cotidiano, e principalmente, desafiar a percepção habitual da arte/ficção e da vida pragmática bem como o que constitui a separação entre ambos os campos. Os acontecimentos cênicos evidenciam a problematização do signo representacional, signo este que encontra-se no eixo da prática teatral dramática tradicional, pois segundo Szondi (2001, p.31) "a relação espectador-drama conhece somente a separação e a identidade perfeitas, mas não a invasão do drama pelo espectador ou a interpolação do espectador pelo drama"

Dada a estrutura analisada o objetivo do espetáculo não é contar a história do assassinato, mas usar esta história como pretexto para desafiar a percepção do público acerca do espaço urbano, do espaço teatral e do espaço midiático. Como já dito, não é preciso ir atrás do significado da história, e sim entender os questionamentos colocados através de sua forma de apresentação. É necessário entender como a apresentação problematiza o espetáculo da cidade e do teatro para poder realçar as relações sociais que se encontram no fundamento de ambos. Deste modo, é possível atender ao sonho de Debord acerca da criação de imagens que possam liberar as experiências humanas e desconstruir a lógica do espetáculo.

\section{Referências Bibliográficas:}

CONARGO, Oscar. O teatro de ação ou as ficções reais. Camarim - publicação da cooperativa paulista de teatro, São Paulo, n 39, ano 10, semestre 2007, p. 26-33

DEBORD, Guy. A sociedade do espetáculo. Rio de Janeiro: Contraponto, 1997.

FINTER, Helga. A teatralidade e o teatro. Camarim - publicação da cooperativa paulista de teatro, São Paulo, n 39, ano 10, semestre 2007, p. 8-19

LEHMANN, Hans-Thies. Teatro pós-dramático. Trad. Pedro Süssekind. São Paulo: Cosac \& Naify, 2007. 
MARINIS, Marco de. El nuevo teatro, 1947 - 1970. Buenos Aires: Ediciones Paidos, 1987.

PRIMAVESI, Patrick. "Orte und Strategien postdramatischer Theaterformen." In: ARNOLD, Heinz Ludwig (org.) Theater fürs 21. Jahrhundert. München: Edition Text + Kritik, 2004, p. 8 - 25.

SZONDI, Peter. Teoria do drama moderno [1880 - 1950]. Trad. Luiz Sérgio Repa. São Paulo: Cosac \& Naify, 2001. 